\title{
DISCUTINDO O CUIDADO AO RECÉM-NASCIDO E SUA FAMÍLIA NO MÉTODO MÃE-CANGURU
}

\author{
DISCUSSING NEWBORN AND FAMILY CARE IN THE KANGAROO MOTHER \\ METHOD
}

Freitas JO, Camargo CL. Discutindo o cuidado ao recém-nascido e sua família no Método MãeCanguru. Rev Bras Crescimento Desenvolv Hum 2006; 16(2):88-95.

\begin{abstract}
Resumo: A permanência de recém-nascidos prematuros ou com muito baixo peso por tempo prolongado nas unidades neonatais até alcançarem o peso ideal para alta hospitalar caracteriza uma situação que pode trazer implicações para a saúde da puérpera e de seu bebê, tais como desestímulo ao aleitamento materno; rompimento do vínculo afetivo, e risco aumentado para infecções. Com o Método Mãe-Canguru (MMC), os RN prematuros e de baixo peso passam a ter contato direto com a mãe, desde o momento em que apresentem condições clínicas estáveis. Com o desenvolvimento e a estabilidade clínica do recém-nascido, o contato pele a pele é iniciado e o bebê permanece junto à mãe numa bolsa semelhante à de um canguru. Dentro do processo de implementação do Método Mãe-Canguru no Brasil, a enfermagem tem contribuído para o sucesso deste programa a partir de uma assistência pautada no envolvimento, dedicação e humanização do cuidado, proporcionando maior aproximação entre a família, o bebê prematuro e a equipe de saúde. Este artigo discute o cuidado de enfermagem ao recém-nascido e sua família no MMC e as dificuldades encontradas na prática para inserção da mãe e seu filho neste método de assistência, com base na experiência de um serviço. Tem a finalidade de promover uma reflexão sobre o papel da enfermagem no MMC, assim como apontar algumas dificuldades encontradas na aplicação do método.
\end{abstract}

Palavras-chave: Método mãe-canguru. Recém-nascido prematuro. Enfermagem neonatal.

\section{O método mãe canguru}

"Foi como se eu pudesse colocá-lo de volta no meu útero para que ele crescesse saudável". Estas foram palavras de uma mãe que carregava seu filho prematuro amarrado contra o seu peito na posição canguru.

O Método Mãe-Canguru consiste no contato direto, pele a pele, entre o recém-nascido prematuro e/ou de baixo peso e sua mãe, desde o momento em que o bebê apresente condições clínicas estáveis. Com o desenvolvimento e a estabilidade clínica do recém-nascido, o contato pele a pele é iniciado e o bebê permanece junto à mãe, como se estivesse em uma bolsa semelhante à de um canguru. Este contato entre mãe e bebê estimula o ganho ponderal de forma mais acelerada, a partir do controle da termor-

Enfermeira. Especialista em Enfermagem Neonatal. Mestranda em Enfermagem - Escola de Enfermagem da Universidade Federal da Bahia (EEUfba). Endereço: Rua das Palmeiras, 90, Cond. Belleville, Torre Marrom, Apto. 201, Cep: 44045-080. Tel: (075) 36225586. E-mail: julidefreitas@hotmail.com.

** Professora Adjunta da Escola de Enfermagem da Universidade Federal da Bahia (EEUfba). Doutora em Saúde Publica pela Faculdade de Saúde Publica da Universidade de São Paulo (USP). 
regulação e da promoção do aleitamento materno. Além disso, o contato entre o binômio estimula o desenvolvimento, o fortalecimento do vínculo afetivo e a aprimoração do cuidado materno.

Segundo Montagu ${ }^{1}$, pesquisas revelam que se um prematuro for tocado, embalado, acariciado ou aconchegado no colo apresenta menos períodos de apnéia, goza de um aumento acelerado do peso e progride em termos do funcionamento do sistema nervoso central.

Com a implementação do MMC como terapêutica assistencial na recuperação de crianças prematuras e de baixo peso, estes recém-nascidos internados em Unidades Neonatais deixam de ser mantidos nas incubadoras até alcançarem o peso considerado ideal para alta, situação esta que trazia implicações para a saúde da puérpera e seu bebê, tais como o desestímulo ao aleitamento materno, comprometimento do vínculo afetivo, além do risco aumentado para infecções, por conta do tempo de permanência prolongado nas unidades de internamento.

Segundo Klaus e Kennel², os recémnascidos pré-termo eram isolados de suas mães e demais familiares, não havendo uma preocupação em aproximar os pais de seus filhos. $\mathrm{O}$ atendimento ao pré-termo era baseado no menor manuseio possível e isolamento, não sendo permitido o contato dos pais com o recém-nascido e excluindo a mãe dos cuidados com o bebê. Hoje, a participação os pais no tratamento e recuperação da criança prematura é vista como essencial para a obtenção de um bom resultado no seu crescimento e desenvolvimento.

A posição canguru, conforme a norma do Ministério da Saúde (MS), traz muitas vantagens para a criança ${ }^{3}$ : aumento do vínculo mãefilho a partir do menor tempo de separação do binômio; estímulo ao aleitamento materno; maior confiança e competência dos pais no cuidado do seu filho após a alta; melhor controle da termorregulação; menor número de RN em uni- dades de cuidados intermediários devido a maior rotatividade dos leitos; melhor relacionamento da família com a equipe; além da redução dos riscos para infecção devido a menor permanência hospitalar. O método canguru permite ainda a estimulação da respiração do RN prematuro, segurança e equilíbrio ao bebê, economia devido a ótima relação custo-benefício, diminuição da mortalidade neonatal ${ }^{4}$.

O Método Mãe-Canguru foi implementado inicialmente em 1978, em Bogotá, na Colômbia por Edgar Rey Sanabria, sendo desenvolvido a partir de 1979 pelos pediatras colombianos Héctor Martínez Gómez e Luis Navarrete Pérez, do Instituto Materno-Infantil de Bogotá. O objetivo deles era acabar com a prática de colocar dois ou três bebês numa mesma incubadora, e ainda reduzir o tempo de separação entre a mãe e a criança, motivo de abandono desses recém-nascidos. Esta técnica foi progressivamente conduzindo à definição do Programa Mãe-Canguru ${ }^{5}$.

Segundo Oliveira ${ }^{6}$, a "posição canguru” idealizada em Bogotá foi baseada no princípio de que os filhotes do animal canguru nascem imaturos e completam seu desenvolvimento no interior de uma bolsa, na qual o filhote é amamentado, aquecido e protegido adequadamente até o momento ideal para sobrevivência fora do ventre materno. O objetivo era diminuir a mortalidade neonatal elevada naquele país. A idéia era de que a colocação do recém-nascido contra o peito da mãe promoveria maior estabilidade térmica, substituindo as incubadoras, permitindo alta precoce, menor taxa de infecção hospitalar e conseqüentemente melhor qualidade da assistência com menor custo para o sistema saúde.

No Brasil, uma das primeiras instituições hospitalares a trabalhar com a posição canguru, foi o Instituto Materno-Infantil de Pernambuco - IMIP, na cidade do Recife. A partir de então, hospitais brasileiros começaram a realizar o método, colocando os recém-nascidos em 
contato com o peito das mães, requerendo capacitação de profissionais e sensibilização da família para evitar o uso de metodologia e critérios inadequados.

A consolidação do Método Mãe-Canguru (MMC) no Brasil pelo Ministério da Saúde no ano de 2002, se deu através do Programa de Humanização do Pré-natal e Nascimento, Portaria $n^{\circ}$ 693, sendo nomeado de Programa de Atenção Humanizada ao Recém-nascido de Baixo Peso ${ }^{3}$. Desde então, o contato precoce dos pais com o recém-nascido prematuro passou a ser uma ação terapêutica da assistência neonatal em nosso país.

Trabalho como enfermeira numa instituição que há mais de dois anos vem buscando desenvolver o Método Mãe-Canguru. A partir da prática diária e dos conhecimentos adquiridos neste período, tenho observado algumas dificuldades que permeiam esta nova estratégia de cuidado humanizado à mãe, filho e sua família. Assim, procurei discutir neste artigo, o cuidado de enfermagem ao recém-nascido e sua família no Método Mãe-Canguru, assim como as dificuldades encontradas na prática para inserção da mãe e seu filho prematuro neste método de assistência.

$\mathrm{O}$ artigo tem como finalidade promover uma reflexão sobre a importância da atuação dos profissionais de enfermagem no MMC, além de apontar obstáculos na aplicabilidade do método.

\section{Discutindo o cuidado dos profissionais de enfermagem no método mãe canguru}

A enfermagem contemporânea vem buscando estabelecer o cuidado como seu objeto de trabalho, conforme afirma Waldow?: "O cuidar foi, por um período, uma característica da enfermagem e, hoje, tenta-se resgatá-lo, tanto no seu conhecimento como em sua arte" (p. 64). A ação de cuidar vem sendo desenvolvida pela enfermagem em diversas áreas de conhecimen- to, dentre estas, a Perinatologia, ciência direcionada ao bem-estar do ser humano desde a concepção até o primeiro mês de vida.

Os avanços nos conhecimentos da saúde perinatal mostraram outras necessidades que não apenas a de vitalidade do bebê, mas também a de um ser que precisa estabelecer relações com a família, a equipe e a sociedade, o que lhe dá direitos universais de cidadania 4 .

O avanço tecnológico e científico ocorrido no século XX proporcionou o fortalecimento da Perinatologia, e todas essas mudanças refletiram-se em maiores taxas de sobrevida de recém-nascidos cada vez mais imaturos e de menores pesos de nascimento, levando unidades neonatais a introduzirem normas e rotinas direcionadas a obtenção de melhores padrões de evolução desses recém-nascidos em longo prazo $^{8}$. Neste contexto, a enfermagem, junto à equipe multidisciplinar, vem contribuindo para a redução da morbimortalidade de recém-nascidos de risco a partir do cuidado prestado a esses bebês e suas famílias.

Segundo Fontes et $\mathrm{al}^{9}$, o nascimento de uma criança hígida e sadia, sua sobrevivência e desenvolvimento normal constituem o objetivo da Enfermagem Perinatal. A enfermagem acompanha o crescimento e desenvolvimento da criança desde a gestação, passando pelo parto, e chegando ao período neonatal, possuindo desta forma importante papel na assistência a saúde do recém-nascido.

O cuidar da criança visa promoção, manutenção e recuperação de seu processo de desenvolvimento, de modo a propiciar seu melhor funcionamento pessoal e social. A satisfação da criança em qualquer faixa etária implica o envolvimento da família no cuidado, pois em nossa sociedade, esta é responsável pelo bemestar e segurança dos seus membros. Nessa perspectiva, a enfermeira interage com a criança e sua família permitindo que eles tenham papel ativo no processo de cuidar ${ }^{10}$.

Dentro do processo de implementação 
do Método Mãe-Canguru no Brasil, desde a década de 90, a enfermagem tem participado deste programa fazendo parte da equipe multidisciplinar de atenção à díade mãe e bebê prematuro. Com o MMC a enfermagem ganha mais um espaço de atuação na assistência ao recémnascido e tem como função cuidar da criança e de sua família sob os aspectos biológicos, proporcionando melhor adaptação à vida extra-uterina, e psicossociais a partir de uma assistência pautada no envolvimento, na dedicação e na humanização do cuidado, promovendo uma aproximação maior entre a família, o bebê prematuro e a equipe de saúde.

Nos últimos 10 anos as discussões em torno da humanização do parto e nascimento foram ampliadas e difundidas contribuindo significativamente para a implantação de uma assistência focada não apenas na doença do recém-nascido e nos equipamentos que ele necessita, mas também na estimulação precoce do vínculo entre o bebê e sua família.

Segundo Klaus e Kennel² , a criação das incubadoras e das unidades de cuidado intensivo possibilita a sobrevivência de recém-nascidos com pesos cada vez mais baixos. Nessas circunstâncias, rotinas hospitalares que separam os pais de seus filhos podem ter implicações negativas para a formação do vínculo afetivo e, conseqüentemente, influenciar o posterior cuidado dessas crianças pelos pais. Na prática posso observar o quanto é importante a presença e o contato dos pais na recuperação do recém-nascido, e a enfermagem tem se empenhado na estimulação do vínculo familiar nas unidades neonatais.

De acordo com Ferreira e Vieira ${ }^{11}$, é de extrema importância que haja uma prevenção de quadros de privação entre mãe e filho, visto que o comportamento afetuoso é um fator que auxilia no desenvolvimento da criança e nas atitudes de maternagem. E a enfermagem pode ser facilitadora neste processo, uma vez que se relaciona diretamente com essa díade e pode perceber a importância e a influência que um exerce sobre o outro.

O papel dos profissionais de enfermagem na estimulação do recém-nascido e no fortalecimento do vínculo com a família implica em promover um cuidado individualizado, minimizando estressores ambientais. Segundo Gaiva e Gomes ${ }^{4}$, o cuidado individualizado tem elementos que impõem modificações no ambiente para reduzir os níveis de som e luz, organização do cuidado de forma a reduzir as atividades, utilização de estratégias específicas para facilitar a auto-organização do bebê e o envolvimento dos pais, a partir de um plano de cuidados individual conforme as respostas da criança aos procedimentos.

Intervenções como manter a melhor posição do recém-nascido com "ninhos” que lhe proporcione segurança; implementar cuidados em etapas; observar o estado comportamental do bebê antes, durante e após procedimentos; estimular visitas e participação dos pais no cuidado são algumas estratégias utilizadas pela enfermagem neonatal na estimulação do recémnascido e no fortalecimento do vínculo familiar.

Nos primeiros dias de internamento na unidade de alto risco, que constitui a primeira etapa do MMC, os prematuros são submetidos a muitos estressores ambientais e assistenciais, valendo ressaltar ainda que, o contato com os pais se limita ao simples toque, o que torna este estímulo materno e paterno prejudicados. Na medida em que o RN estabiliza-se clinicamente e esta criança é transferida para a segunda etapa do Método Canguru, o contato dos pais com seu bebê prematuro é mais intenso. Neste momento, os profissionais de enfermagem tem a grande responsabilidade de ensinar os pais a cuidarem do seu filho preparando-os para a futura alta para casa.

Cuidar de crianças cada vez mais prematuras vem sendo um desafio para a enfermagem no que tange o cuidado a este recém- 
nascido e sua família, que, na maioria das vezes, está dominada por sentimentos perturbadores e contraditórios ${ }^{12}$. Segundo Daré Junior et $\mathrm{al}^{13}$, o nascimento de um bebê prematuro muitas vezes não é um acontecimento previsível para os pais. Durante a gestação os pais sonham com uma criança perfeita, idealizada, e o nascimento prematuro causa forte impacto emocional e grande estresse na família. Sendo assim, o cuidado dispensado aos pais destes recém-nascidos é uma tarefa difícil para os profissionais, e normalmente, após o seu nascimento, os pais vêem seus ideais abalados, já que o filho sonhado não aconteceu $^{14}$.

Xavier $^{15}$, refere que o MMC é um cuidado complementar ao tratamento de alta tecnologia. Pedagogicamente cria condições que permitem às mães vivenciar o saber fazer e se responsabilizar. Deve-se entender que é uma proposta incentivadora da assistência ambulatorial e está na perspectiva de desmedicalização e desospitalização do cuidado.

A implementação das diretrizes do MMC preconizadas pelo Ministério da Saúde pressupõe equipes de saúde com habilidades não só para a prática do método nas unidades neonatais, mas também para lidar com os aspectos que podem influenciar o ato de cuidar no âmbito da família ${ }^{16}$.

Para alcançar este modelo ideal de atenção à puérpera e seu filho prematuro, a enfermagem muitas vezes se defronta com alguns obstáculos para a concretização do programa, a exemplo das dificuldades na adesão das famílias ao método e as próprias barreiras institucionais.

Toma ${ }^{16}$ diz que o MMC trata essencialmente do cuidar. Tendo em vista que as mulheres são as cuidadoras primárias da criança, cabe uma reflexão sobre os aspectos que poderiam influenciar a prática do MMC enquanto resultados de sua interação com a equipe hospitalar e os membros da família.

\section{Dificuldades observadas na prática para inserção da família no método mãe canguru}

O MMC pode ser considerado uma metodologia ideal de atenção ao recém-nascido de baixo peso e sua família; no entanto, como enfermeira assistencial de uma maternidade pública, percebo que a adesão ao método implica uma série de critérios necessários que nem sempre podem ser cumpridos integralmente. Situações como a alta demanda de partos na rede pública de saúde, a moradia dos pais em lugares muito afastados, a existência de outros filhos no domicílio, a ausência de um companheiro ou do apoio familiar e a ocorrência de partos prematuros em mães adolescentes constituem alguns fatores que podem promover uma resistência materna para realização do método, levando os profissionais de saúde a enfrentarem muitas dificuldades para conseguir a adesão da família.

Para Toma ${ }^{16}$, o processo de decisão para a prática do MMC é complexo, e depende não só da vontade da mãe, mas também do apoio de sua rede familiar e de uma equipe de saúde compreensiva. Embora as mães, na maioria dos casos, percebam a importância do método para a recuperação de seus filhos, os dilemas e as dificuldades pessoais e de ordem familiar podem impedi-la de participar efetivamente do programa.

No Brasil, a saúde pública tem enfrentado sérios problemas decorrentes do reduzido número de leitos obstétricos para uma excessiva demanda de partos. A mídia mostra freqüentemente mulheres em busca de um leito hospitalar para parir, e até registros de partos ocorridos em trânsito por conta desta peregrinação. Associado a este fato encontra-se a deficiência de leitos de internamento neonatal, já que existe um número considerável de nascimentos de bebês com algum tipo de patologia.

Dentre as patologias neonatais, a prema- 
turidade merece destaque pela sua alta incidência. Segundo o Ministério da Saúde, nascem anualmente 20 milhões de crianças prematuras e com baixo peso no mundo. A pobreza, a deficiência na atenção pré-natal, a alta taxa de fecundidade entre adolescentes, podem ser consideradas algumas das principais causas de parto prematuro no Brasil. Bittar e Zugaib ${ }^{17}$ referem o baixo nível sócio-econômico, más condições de higiene, nutrição inadequada, gravidez na adolescência ou indesejada, conflitos familiares, fumo, consumo de drogas, estresse constante e a falta de atenção pré-natal adequada, como fatores de risco epidemiológicos associados a prematuridade.

Conforme Gaiva e Gomes ${ }^{4}$, nos paises em desenvolvimento, como o Brasil, os bebês prematuros encontram grande escassez de recursos, infra-estrutura inadequada, superlotação, infecção hospitalar e conseqüentemente elevados índices de morbimortalidade.

Na prática observo que a ocorrência de um nascimento prematuro traz altos custos para o sistema de saúde pública, já que os gastos com o internamento de um bebê pré-termo é elevado e muitos estados brasileiros ainda não dispõem de leitos hospitalares adequados para assistir estas crianças e suas famílias. Este fato acaba gerando situações de alta precoce de recém-nascidos para possibilitar o internamento de outros mais necessitados.

Com o MMC, numa situação de superlotação em berçários, os bebês prematuros após estabilização clínica na primeira etapa são logo transferidos para a segunda etapa do método, e muitas vezes não obedecem a um dos critérios de elegibilidade preconizados pelo Ministério da Saúde, que é o peso mínimo de 1250 g.

Critérios relacionados à mãe também merecem discussão. nem sempre elas têm total disponibilidade para permanecer todo o tempo na instituição acompanhando o RN prematuro, seja pela existência de outros filhos para cuidar, por morar em municípios distantes, ou pela fal- ta do apoio de um companheiro ou algum membro da família. Estes fatores podem levar a uma adesão quase forçada da mãe ao MMC, desobedecendo a um dos princípios mais importantes do programa que é o prazer de mãe e filho na realização deste método.

Estudo realizado por Rea e Toma ${ }^{18}$, em 1997, que tratava de um projeto piloto sobre a viabilidade da implantação do MMC em maternidade pública da cidade de São Paulo apontou a presença de outros filhos e a falta de dinheiro para o transporte como algumas dificuldades para a participação das mães.

Outra questão que merece ser discutida é a falta de orientação às mulheres com gravidez de risco para prematuridade. O acompanhamento pré-natal inadequado e de má qualidade muitas vezes não permite que essas gestantes sejam orientadas quanto ao tempo de permanência de um bebê prematuro numa instituição hospitalar, e quanto aos riscos que a prematuridade pode oferecer a uma criança. Em alguns casos elas chegam à maternidade em trabalho de parto prematuro buscando apenas uma incubadora que seu filho possa ficar após nascer, sem ter conhecimento das reais necessidades desta criança, dos riscos de um nascimento prematuro, e principalmente, do seu importante papel junto à equipe de saúde neonatal na recuperação do seu filho.

Vale neste momento ressaltar a ocorrência de nascimento prematuro em mulheres adolescentes. Ser mãe adolescente, e de um bebê prematuro, são dois eventos adversos numa fase de vida cercada de alterações biopsicossociais, assim, a recuperação do vínculo afetivo entre mãe e filho e a preparação materna para o cuidado da criança prematura pode tornar-se mais difícil para mães muito jovens.

Klaus e Kennell ${ }^{2}$ referem que os pais precisam reconciliar sua imagem mental idealizada do bebê esperado com o bebê real, muito pequeno e frágil, sendo difícil para eles acreditarem que seu filho poderá crescer normal. Dian- 
te disto, um curto período de tempo, os profissionais tentam educar pais e mães para cuidarem de um bebê pré-termo bem diferente daquele que sonharam ter nos braços após o nascimento, e esta é uma tarefa que requer preparo e conhecimento da equipe de saúde.

\section{CONSIDERAÇOES FINAIS}

O Método Mãe Canguru, nomeado pelo Ministério da Saúde como Programa de Atenção Humanizada ao Recém-nascido de Baixo Peso, proporcionou fortalecimento de algo que vem sendo discutido na prática do cuidado ao recém-nascido em estado de enfermidade e sua família, que é uma atenção focada não apenas nos avanços tecnológicos alcançados ao longo dos últimos anos, mas também na humanização da assistência, baseada principalmente na reaproximação dos pais com seus filhos nas unidades de internamento hospitalar.

Para Ferreira e Vieira ${ }^{11}$, o MMC contribui pra a indissolubilidade da relação mãe e filho, zelando pelo apego desta díade e promovendo vantagens sociais e econômicas. Equipes multiprofissionais e principalmente enfermeiros que estão em contato contínuo com o paciente poderiam promover e efetivar a utilização do método canguru como um programa para ajudar na recuperação do recém-nascido e na valorização da participação dos pais no cuidado, a fim de se garantir o apego bem como realizar uma abordagem holística do paciente, cuidando do físico, do social e do emocional doindivíduo.
Toma ${ }^{16}$ refere que o MMC traz muitos benefícios ao bebê prematuro e/ou de baixo peso e às famílias. A oportunidade de uma participação efetiva dos pais favorece o fortalecimento do vínculo, bem como a possibilidade de elaborar arranjos mais favoráveis para o cuidado da criança. Além disso, o MMC traz vantagens na assistência neonatal no que diz respeito ao incentivo do aleitamento materno, à redução de custos hospitalares, à redução nos índices de infecção hospitalar e morbimortalidade neonatal. Entretanto, na prática, existem questões relativas à criança e à família que podem comprometer a realização do MMC.

A enfermagem, junto à equipe multidisciplinar, tem desempenhado papel fundamental na implementação do MMC e no fortalecimento do vínculo afetivo entre o bebê e sua família, vínculo este que se inicia desde a gestação e pode estar comprometido após o nascimento prematuro. Cabe à enfermagem ensinar os pais a compreender este processo antecipado do nascimento e prepará-los para o cuidado após a alta para casa. Para tal, os profissionais têm enfrentado dificuldades na adesão dos pais ao MMC devido ao contexto no qual esta família pode estar inserida.

Mesmo diante das barreiras encontradas na prática para a inserção do recém-nascido e sua família no MMC, os benefícios que este programa traz para a díade mãe-filho podem superar as dificuldades, e nós, profissionais de saúde, devemos compreender que o envolvimento psicossocial da equipe e da família são primordiais para o sucesso desta nova estratégia de cuidado humanizado.

\footnotetext{
Abstract: The permanence of premature or very low weight newborn babies for a long time in neonatal units until they reach the ideal weight for hospital discharge characterizes a situation that can bring implications for the mother's and her baby's health, such as breastfeeding discouragement, breaking of the affective bond and increased risk of infections. With the Kangaroo Mother Method (KMM), the premature newborn and the low weight babies have direct contact with their mothers as soon as they present stabilized clinical conditions. The skin-to-skin contact is initiated, and the baby stays close to the mother in a bag similar to that of a kangaroo. In the implementation process of the Kangaroo Mother Method in Brazil, the nursing sector has been
} 
contributing for the success of the program providing assistance based on involvement, dedication, and care humanization, thus bringing more proximity between family, premature baby and health staff. This article discusses the nursing care given to the newborn and the family in the KMM, and the difficulties found in the insertion of mother and child in this assistance method. The present study also intends to reflect on the importance of the nursing professionals' performance in the KMM program, as well as to point out some difficulties in the application of the method.

Key-words: Kangaroo Mother Method. Premature newborn. Neonatal nursing care.

\section{REFERENCIAS}

1. Montagu A. Tocar: o significado humano da pele. $8^{\text {a }}$ ed. São Paulo: Summus; 1988.

2. Klaus MH, Kennel JH. Pais/bebê: a formação do apego. Porto Alegre: Artes Médicas; 1993.

3. Ministério da Saúde. Atenção humanizada ao recém-nascido de baixo peso: método mãecanguru. Brasília (DF); 2002.

4. Gaíva MAM, Gomes MMF. Cuidando do neonato: uma abordagem de enfermagem. Goiânia: AB; 2003.

5. Charpak N, Calume ZF, Hamel A. O método mãe-canguru. Rio de janeiro: McGraw-Hill; 1996.

6. Oliveira ND. Como o Brasil trabalha o método mãe canguru. Disponível em: http://www.metodocanguru.org.br/ historico.htm [acesso em 16 abr 2006].

7. Waldow VR. O cuidado humano: o resgate necessário. Porto Alegre: Seagra Luzzatto; 1998.

8. Leone CL. Epidemiologia, desafios e perspectivas. In: Costa HPF, Marba ST, coordenadores. O recém-nascido de muito baixo peso. São Paulo: Atheneu; 2004. p. 3-10.

9. Fontes JAS, organizador. Perinatologia social. São Paulo: Fundo Editorial BYK Proceinx; 1984.

10. Verissimo MDLR, Sigaud CHS. O processo de cuidar centrado na criança. In: Verissimo MDLR, Sigaud CHS, organizadores. Enfermagem pediátrica: o cuidado de enfermagem à criança e ao adolescente. São Paulo: EPU; 1996. p. 83-7.

11. Ferreira L, Vieira CS. A influência do método canguru na recuperação do recém-nascido em unidade de terapia intensiva neonatal: uma revisão de literatura. Acta Sci, Health Sci. 2003;25(1):41-50.
12. Rego JD. Assistência aos pais de recémnascidos prematuros, doentes, malformados. [S.l.]: Nestlé - Serviço de Informação Científica; 1991. (Temas de Pediatria, n. 48).

13. Daré Junior S, Imamura PE, Figueira BB, Fernandes GC. Humanização e abordagem desenvolvimentista nos cuidados ao recémnascido de muito baixo peso. In: Costa HPF, Marba ST, coordenadores. O recém-nascido de muito baixo peso. São Paulo: Atheneu; 2004. p. 85-102.

14. Alves AMA. Quando o bebê que chega não é o sonhado. In: Figueiredo NMA. Ensinando a cuidar da mulher, do homem e do recémnascido. São Paulo: Difusão Paulista de Enfermagem; 2003.

15. Xavier CC. O método cuidado mãe canguru [texto na Internet]. Belo Horizonte: Departamento de Pediatria da Faculdade de Medicina da UFMG; 2004 [acesso em 18 abr 2006]. Disponível em: http://www.medicina.ufmg.br/edump/ped/ canguru.htm.

16. Toma TS. Método mãe canguru: o papel dos serviços de saúde e das redes familiares no sucesso do programa. Cad Saúde Pública. 2003;19(Supl 2):233-42.

17. Bittar RE, Zugaib M. Parto prematuro: fatores predisponentes e prevenção. In: Marcondes E, Vaz FAC, Ramos JLA, Okay Y, coordenadores. Pediatria básica: pediatria geral e neonatal. $9^{a}$ ed. São Paulo: Sarvier; 2002. p. 337-45.

18. Rea MF, Toma TS. Assistência canguru: desenvolvimento de um projeto piloto na cidade de São Paulo e estudo de custoefetividade: relatório técnico. São Paulo: Instituto de Saúde; 1997. 